\title{
USE OF RENEWABLE ENERGY IN THE EUROPEAN UNION - TRENDS OF CHANGE
}

\author{
Arkadiusz Gromada ${ }^{1}$, M.Sc.; Paulina Trebska², M.Sc. and Marcin Wysokinski ${ }^{3}$, Ph.D.
}

$1,2,3$ Warsaw University of Life Science

\begin{abstract}
Purpose of the article was to assess the use of energy from renewable sources in the European Union Member States in 2004-2016. Changes in the structure of renewable energy carriers are presented, indicating the directions of changes. A high concentration of renewable energy consumption in the European Union was found. The share of renewable energy in total energy consumption in all EU countries was increasing, but not all countries are able to achieve the national targets. The main source of renewable energy in the European Union was biomass, and its share in the total structure of renewable energy was about $45 \%$. A weak relationship between the share of renewable energy in final gross energy consumption and the Human Development Index (HDI) was also found.
\end{abstract}

Key words: renewable energy, renewable energy sources, European Union, energy.

JEL codes: $013, \mathrm{P} 18$.

\section{Introduction}

Access to energy resources and security of energy supply are the main conditions contributing to socio-economic progress. This is particularly evident in the case of the European Union, which established its energy policy on the basis of these two criteria. However, economic development and associated energy use, mainly derived from non-renewable sources, adversely affects the environment. It should also be remembered that exhaustible resources from conventional sources will be reduced the next several decades. The solution enabling the economic growth of the European Union and individual Member States, while respecting the natural environment, is the use of energy from renewable sources. Positive and negative aspects related to the use of renewable energy were discussed by many authors (Wicki L., 2017; Golebiewski J., Rakowska J., 2017; Wysokinski M., Trebska P., Gromada A., 2018). The use of renewable energy sources in various countries is often difficult due to the existence of non-renewable energy sources in a given country (Rokicki T., 2016). It is therefore important to reduce total energy consumption, its rational use and increasing the share of renewable energy sources in total energy consumption. This approach has been included in many directives and regulations issued by European Union institutions and bodies.

One of the objectives of the EU energy policy, in accordance with art. 194 of the Treaty on the Functioning of the European Union (European Union, 2012) is to support renewable forms of energy. This objective is pursued by the directive on the promotion of the use of energy from renewable sources (European Parliament, 2018). This directive is part of the 'Clean energy for all Europeans' legislative package, the introduction of which will contribute to increasing energy efficiency, achieving global leadership in the use of energy from renewable sources by the European Union and creating fair conditions for consumers. This package contains 8 different legislative texts (Clean Energy for all Europeans):

- Directive of 30 May 2018 on the energy performance of buildings,

- Directive of 11 December 2018 on the promotion of the use of energy from renewable sources,

- The Energy Efficiency Directive of 11 December 2018,

- Regulation of 11 December 2018 on the Governance of the Energy Union and Climate Action,

- Electricity Directive,

- Electricity Regulation,

${ }^{1}$ Corresponding author. Email address: arkadiusz_gromada@sggw.pl 
- Risk-Preparedness Regulation,

- Rules for the regulator ACER (Agency for the Cooperation of Energy Regulators).

Pursuant to the directive, the use of energy from renewable sources in total energy consumption in 2030 should amount to $32 \%$. The Commission pointed out that this objective may be increased due to the decrease in energy consumption in the European Union, Union obligations related to decarbonisation or reduction of renewable energy costs. This goal has changed over the past few years. In the Directive of 23 April 2009 on the promotion of the use of energy from renewable sources (European Parliament, 2009), the $20 \%$ share of energy from renewable sources was assumed for 2020. In 2014, the European Commission proposed that this share should be at least $27 \%$ for the year 2030 (European Commission, 2014) but in view of the aspirations set out in the Paris Agreement (United Nations, 2015), the development of technologies related to renewable energy and the reduction of costs in in this sector, the objective set out in the Directive of 11 December 2018 was adopted.

Considering abovementioned objectives of the European Union, it is important to analyse the current state and identify the trends of changes in this area currently taking place in EU Member States.

\section{Research results}

The study adopted five research tasks:

- valuation of the share of renewable energy sources (RES) in the European energy mix,

- estimation of the share of individual carriers of renewable energy sources in the structure,

- establishing groups of European Union member states, depending on the share of renewable energy in the final gross energy consumption and the level of the Human Development Index,

- establishing of the correlation between RES and the Human Development Index (HDI),

- estimation of the concentration of renewable energy in the European Union.

The following research methods were used to implement the above-mentioned tasks:

- literature study,

- Gini index and Lorenz curve,

- Pearson's linear correlation coefficient.

The research was based on data from Eurostat and Human Development Data.

Renewable energy sources are characterized by a growing share of gross energy consumption in the European Union (Figure 1). In all EU countries, share increased in 2016 compared to 2004 by at least 4 p.p. The largest increase took place in Denmark (17.3 p.p.) and Sweden (15.1 p.p.). Furthermore, Sweden was the only country in Europe where the share of renewable energy in the final gross energy consumption was higher than $50 \%$. The average share in 2016 for the entire European Union was $17 \%$ and was twice as high as in 2004, however, it has not yet achieved the 2020 target. Each Member State has set its own target for 2020. These objectives include the starting point, the potential for the development of renewable energy and economic results. Among the 28 countries of the European Union, 11 reached the target set for 2020 in 2016. They were: Bulgaria, the Czech Republic, Denmark, Estonia, Croatia, Italy, Lithuania, Hungary, Romania, Finland and Sweden. In addition, the share of renewable energy in the final gross energy consumption in Austria was 1 p.p. lower than the designated goal. At the other end of the scale are the Netherlands ( 8 p.p. below the target), France (7 p.p.), Ireland (6.5 p.p.), the United Kingdom (5.7 p.p.) and Luxembourg (5.6 p.p.). 


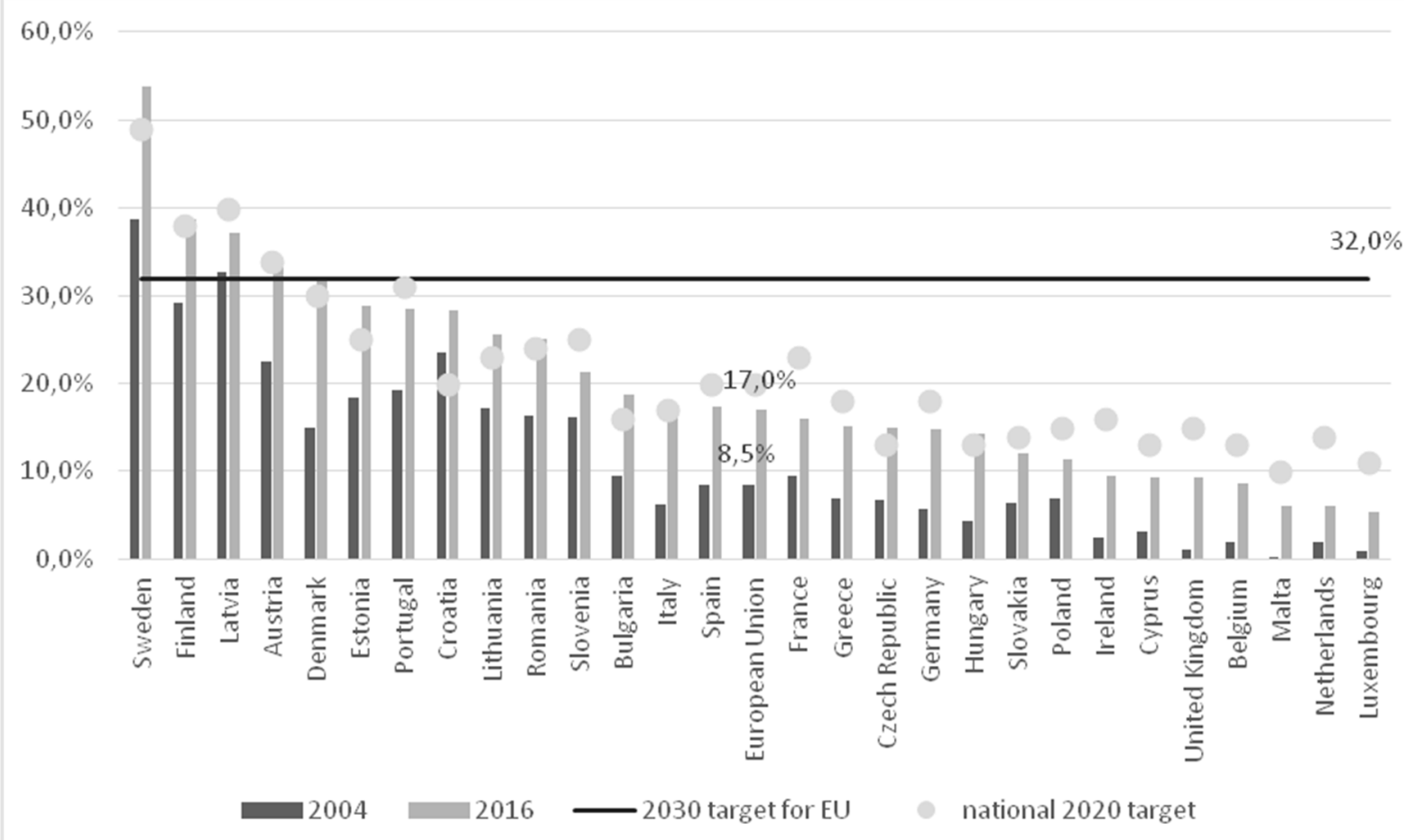

Source: author's calculations based on data from Eurostat

Fig. 1. Share of renewable energy in gross final energy consumption in European Union in 2004-2016

The main source of renewable energy in the European Union was biomass. Its share in the total structure of renewable energy in 2016 amounted to $45.37 \%$, which means a decrease by over 10 p.p. compared to 2004 (Figure 2). However, despite the decline in the share in the structure, biomass consumption in the analysed period increased by nearly $55 \%$, from 63.5 million tonnes of equivalent oil (Mtoe) to over 98 Mtoe. According to a study conducted by the International Renewable Energy Agency (IRENA) in cooperation with the European Commission (IRENA, 2018), it will remain the key source of renewable energy in the EU by 2030. It results from the possibility of wide use of biomass during decarbonisation processes of energy sources in the region, when other solutions are unprofitable. In addition, biomass was the main source of renewable energy in industry, while in transport it was the second largest source.

The fastest growing source of renewable energy in the European Union was solar energy. In 2004, its final gross consumption (sum of solar thermal and photovoltaic solar energy) amounted to 0.7 Mtoe, 12 years later - 13.4 Mtoe (increase by $1825 \%$ ). In the analysed period the energy consumption from liquid biofuels increased nearly six times, while the energy from wind power and biogas increased 4 times. Despite the general trend of the development of renewable energy sources, two of them: water energy and geothermal energy were characterized by small increases (by 6 \% and $26 \%$ respectively). The general structure of energy sources consumption has also changed. Already in 2004, the three main renewable energy sources (biomass, water energy and wind energy) accounted for $85 \%$ of total gross energy consumption of renewable energy. For comparison, in 2016 share was $71 \%$. 


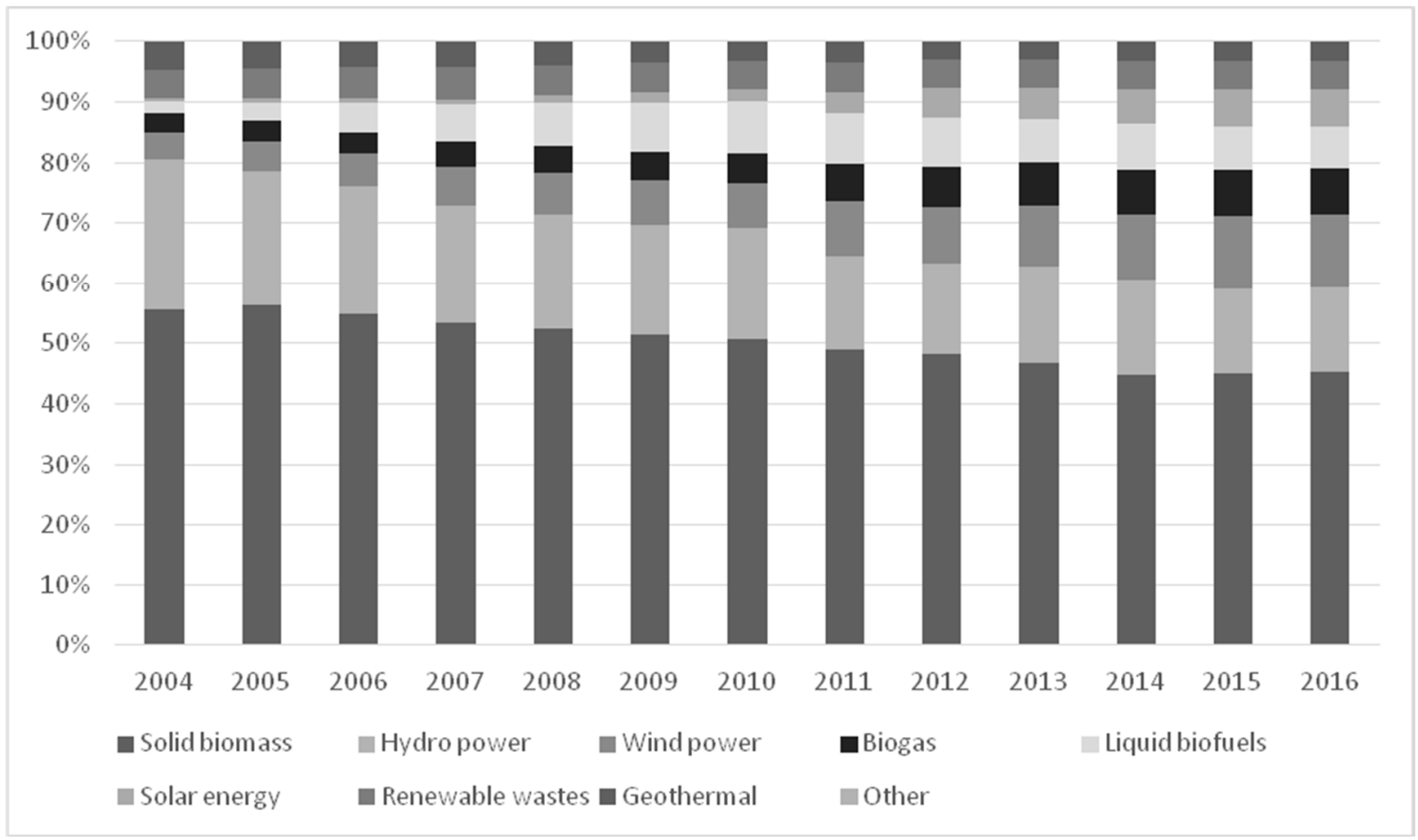

Source: author's calculations based on data from Eurostat

Fig. 2. Share of renewable energy sources in the gross consumption of renewable energy in European Union in 2004-2016

Considering the relation between the share of renewable energy sources in gross energy consumption and the Human Development Index, EU Member States can be divided into four groups (Figure 3):

- Group 1 - countries with an HDI higher than the average for the sample (>0.881393) and the share of renewable energy sources in gross energy consumption higher than the average for the entire European Union (> $19.96 \%$ ),

- Group 2 - countries with an HDI higher than the average for the sample (>0.881393) and the share of renewable energy sources in gross energy consumption lower than the average for the entire European Union ( $<19,96 \%)$,

- Group 3 - countries with an HDI lower than the average for the sample $(<0.881393)$ and the share of renewable energy sources in gross energy consumption higher than the average for the entire European Union (> $19.96 \%$ ),

- Group 4 - countries with an HDI lower than the average for the sample $(<0.881393)$ and the share of renewable energy sources in gross energy consumption lower than the average for the entire European Union ( $<19,96 \%)$.

Group 1 includes such countries as: Sweden, Finland, Denmark, Austria and Slovenia. These are countries with a high level of social development, for years investing in environmental protection and the development of renewable energy sources. Group 2 includes: Germany, Ireland, the Netherlands, the United Kingdom, Belgium, Luxembourg, France, Spain and the Czech Republic, using mostly large amounts of energy, and therefore are forced to diversify energy sources. This affects the smaller role of renewable energy in these countries. Group 3 are countries, such as Latvia, Estonia, Lithuania, Portugal, Croatia and Romania. In these countries, the share of renewable energy in total energy consumption is high and results mainly from geographical values that favour the development of renewable energy (Romania, Croatia, Portugal) and the small area of the country, which partially 
affects the amount of energy consumption (Latvia, Estonia, Lithuania). Countries belonging to Group 4 are small island states characterized by low energy consumption (Malta, Cyprus), countries with relatively high energy consumption, in which the transition from conventional energy sources to renewable sources is gradually but slowly (Bulgaria, Hungary, Slovakia and Poland) and the countries of Southern Europe, which were significantly affected by the financial crisis in the euro area (Italy and Greece).

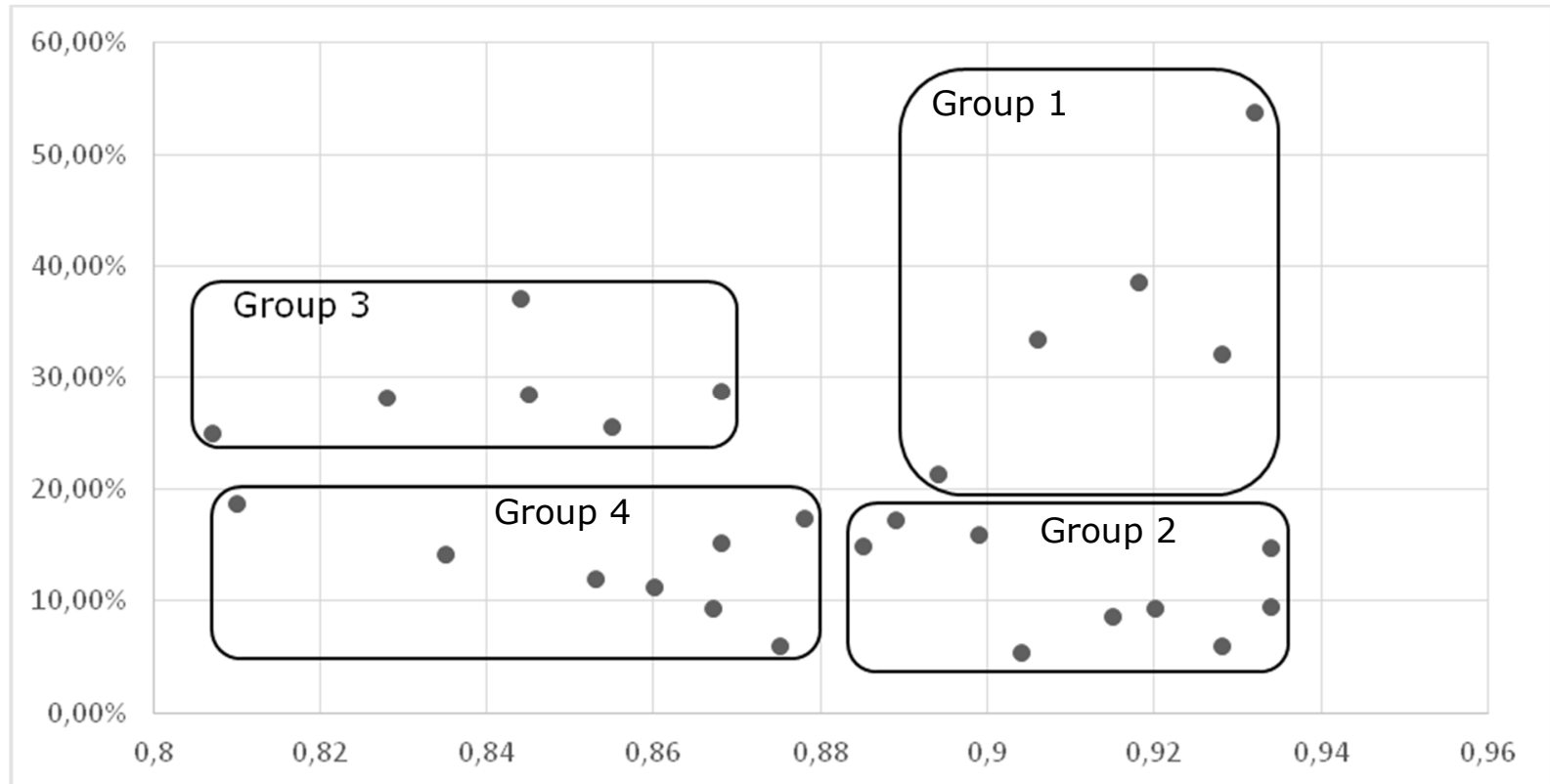

Source: author's calculations based on data from Eurostat and Human Development Data

Fig. 3. Relationship between the share of renewable energy in gross final energy consumption and Human Development Index in European Union in 2016

Pearson's linear correlation coefficients were calculated in 2004, 2008, 2012 and 2016 in order to establish the relation between the share of renewable energy in final gross energy consumption and the Human Development Index. A weak negative relationship between the share of renewable energy in final gross energy consumption and the Human Development Index in the analysed years was found. The social development of a given member state in No way affects the share of renewable energy in final consumption.

Table 1

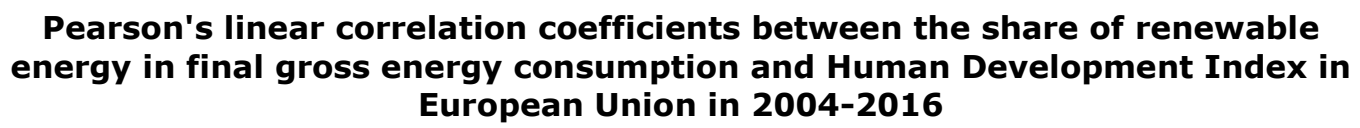

\begin{tabular}{|c|c|c|c|}
\hline \multicolumn{4}{|c|}{ Pearson's linear correlation coefficients for year } \\
\hline 2004 & 2008 & 2012 & 2016 \\
\hline$-0,096$ & -0.036 & -0.056 & -0.029 \\
\hline
\end{tabular}

Source: author's calculations based on data from Eurostat and Human Development Data Source

The Gini coefficient was used to determine the concentration of renewable energy in the European Union. Data on renewable energy consumption for 2016 in 28 EU countries were used. The Gini coefficient for the audited year was 0.59 . This means a high concentration of renewable energy consumption in several European Union countries. Figure 4 presents the concentration of renewable energy consumption in the European Union using the Lorenz curve. On the horizontal axis, the countries of the European Union were classified in an ascending order according to the share in the total consumption of renewable energy. The vertical axis presents the percentage of total consumption of renewable energy in the European Union. In 2016, in nine European Union countries 
$78.5 \%$ of available renewable energy was used (170 Mtoe). These include Germany, Italy, France, Sweden, Spain, the United Kingdom, Finland, Austria and Poland. The first three countries consumed a total of 89.5 Mtoe, which accounted for over $41 \%$ of total consumption. For comparison, 14 countries at the other end of the scale consumed 21.5 Mtoe in 2016, which accounted for less than $10 \%$ of total renewable energy consumption in the European Union.

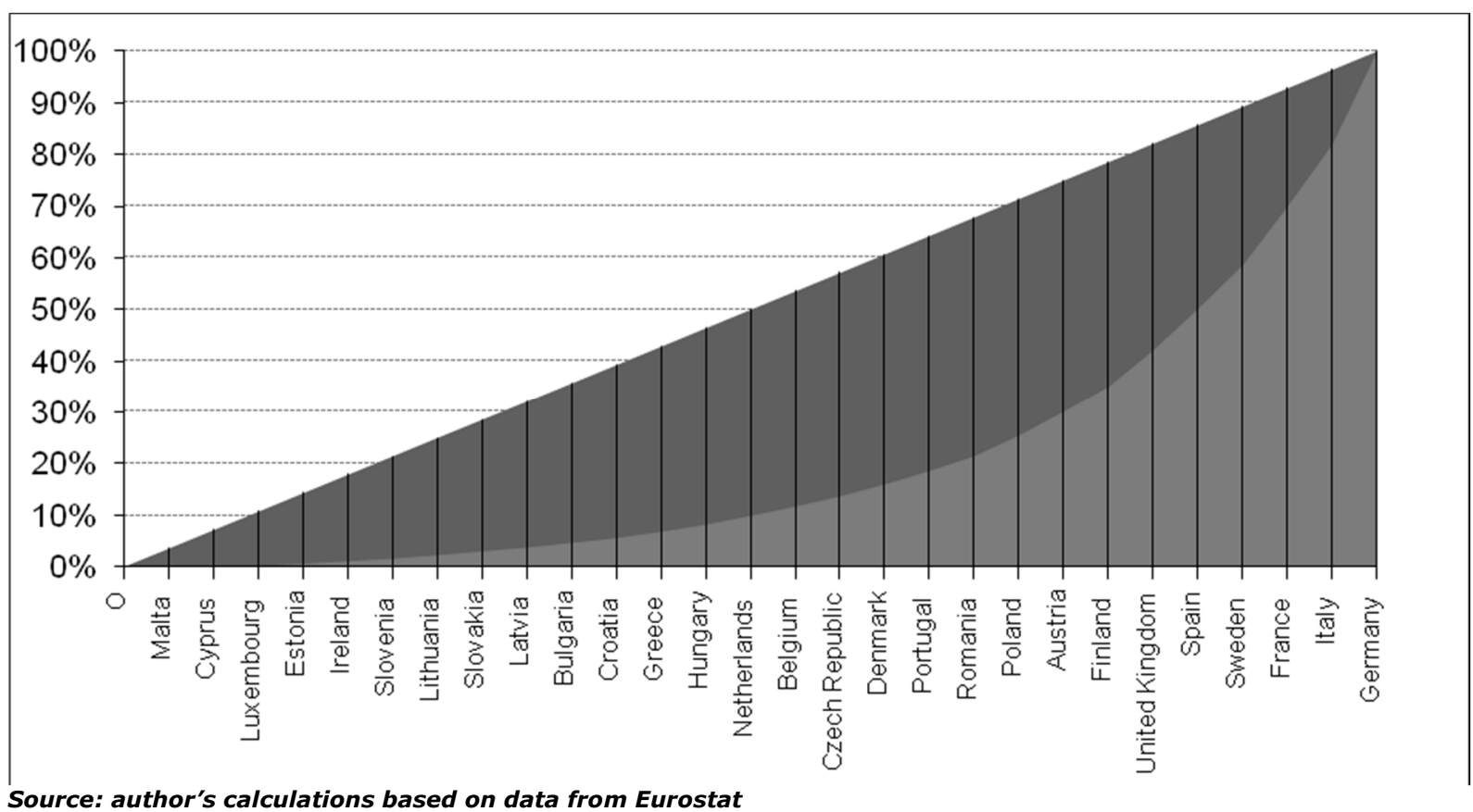

Fig. 4. Concentration of renewable energy consumption in the European Union in 2016

\section{Conclusions, proposals, recommendations}

1) Energy from renewable sources is an important element of the sustainable development strategy of the European Union and the member states. RES are an alternative to traditional primary nonrenewable energy carriers. There is a continuous development of renewable energy throughout the European Union, which is caused by the growing public awareness of the consumption of traditional, conventional energy sources.

2) Methods of using energy from renewable sources depend on the conditions prevailing in a given area, i.e. on wind speed, solar radiation intensity, geothermal resources, accessibility to water. The main source of renewable energy in the European Union was biomass, while solar energy was the fastest-growing renewable energy source. Fast-growing sources were also biofuels, wind energy and biogas. The general structure of consumption of renewable energy sources was also changing.

3) The target set in the directive on the promotion of the use of energy from renewable sources, according to which the use of energy from renewable sources in total energy consumption in 2030 should amount to $32 \%$, was achieved in 2018 by five countries (Sweden, Finland, Latvia, Austria, Denmark), while the next three were close to achieving it (Estonia, Portugal, Croatia).

4) Among the group of countries with the HDI index and the share of renewable energy sources in gross energy consumption higher than the average for the entire European Union, the Scandinavian countries dominated. The studies revealed No positive impact of social development on the increase in energy consumption from renewable sources. 
5) In 2016, a high concentration of renewable energy consumption in the European Union was found - 3 countries with the highest consumption (Germany, Italy, France) were responsible for more than $40 \%$ of total consumption in the EU.

\section{Bibliography}

1. Clean Energy for all Europeans. Retrieved: https://ec.europa.eu/energy/en/topics/energy-strategy-andenergy-union/clean-energy-all-europeans. Access: 06.02.2019.

2. European Commission (2014). Communication from the Commission to the European Parliament, the Council, the European Economic and Social Committee and the Committee of the Regions, A policy framework for climate and energy in the period from 2020 to 2030. Brussels.

3. European Parliament and the Council (2009). Directive 2009/28/EC of the European Parliament and of the Council of 23 April 2009 on the promotion of the use of energy from renewable sources and amending and subsequently repealing Directives 2001/77/EC and 2003/30/EC. Official Journal of the European Union L $140 / 16$.

4. European Parliament and the Council (2018). Directive (EU) 2018/2001 of the European Parliament and of the Council of 11 December 2018 on the promotion of the use of energy from renewable sources. Official Journal of the European Union L 328/82.

5. European Union (2012). Consolidated version of the Treaty on the Functioning of the European Union. Official Journal of the European Union C 326/47.

6. EUROSTAT. Retrieved: http://www.europa.eu. Access: 06.02.2019.

7. Golebiewski, J., Rakowska, J. (2017). Production and Use of Bioenergy in Poland in the Context of the Development of Bioeconomy. Proceedings of the 8th International Scientific Conference: Rural Development 2017, Aleksandras Stulginskis University, Lithuania.

8. Human Development Data. Retrieved: http://hdr.undp.org/en/data. Access: 06.02.2019.

9. International Renewable Energy Agency (IRENA) (2018). Renewable Energy Prospects for the European Union.

10. Rokicki, T. (2016). Sustainable Development in Energy Sector in the European Union Countries. Economic Science for Rural Development. Proceedings of the International Scientific Conference, Jelgava, No 43, pp. 108-116.

11. United Nations (2015). Paris Agreement. 2015 United Nations Climate Change Conference, Paris.

12. Wicki, L. (2017). Food and Bioenergy - Evidence from Poland. Rural Development and Entrepreneurship: Bioeconomy Production and Co-operation in Agriculture. Proceedings of the International Scientific Conference, 27-28 April 2017, Jelgava, Latvia, pp. 299-305.

13. Wysokinski, M., Trebska, P., Gromada, A. (2018). Use of Energy in Polish Agriculture. Rural Development and Entrepreneurship: Production and Co-operation in Agriculture. Proceedings of the International Scientific Conference, 9-11 May 2018, Jelgava, Latvia, pp. 531-536. 